\title{
Comparison of Enzyme Activities in Plasma and Leukocytes in Dairy and Beef Cattle
}

\author{
Toshiro ARAI ${ }^{1)}$, Akira INOUE ${ }^{1)}$, Akira TAKEGUCHI ${ }^{1)}$, Hisashi MIZUTANI ${ }^{2}$, Megumi SHIMOO ${ }^{2)}$, Toshinori SAKO ${ }^{2)}$, \\ Itaru YOSHIMURA ${ }^{3)}$ and Nobuhiro KIMURA ${ }^{4)}$ \\ ${ }^{1)}$ Divisions of Veterinary Biochemistry, ${ }^{2)}$ Veterinary Internal Medicine, Department of Veterinary Science, ${ }^{3)}$ Fuji Animal Farm and \\ ${ }^{4)}$ Division of Animal Nutrition, Department of Animal Science, Nippon Veterinary and Animal Science University, 1-7-1 Kyonancho, \\ Musashino, Tokyo 180-8602, Japan
}

(Received 4 September 2002/Accepted 22 July 2003)

\begin{abstract}
Concentrations of plasma glucose, immunoreactive insulin (IRI) and free fatty acid (FFA) and activities of enzymes related to energy metabolism and lactate dehydrogenase (LDH) isoenzyme pattern in plasma and leukocytes were investigated in lactating Hols tein cows (dairy cattle) and fattening Japanese Black Wagyu x Holstein steers (beef cattle). IRI concentrations and LDH and malate dehydrogenase (MDH) activities in the plasma of beef cattle were significantly higher than those in dairy cattle. The cytosolic rat io of MDH/ LDH activity in the leukocytes of beef cattle was significantly higher than that of dairy cattle. These findings might be associated with the different energy metabolism between dairy and beef cattle.
\end{abstract}

KEY WORDS: beef cattle, insulin, malate dehydrogenase.

It has been reported that activities of enzymes related to energy metabolism including ATP production in peripheral leukocytes are very variable in animal species [23, 24]. In particular, activities of enzymes in the malate-aspartate shuttle, which has a very important role in the transfer from cytosolic NADH to mitochondrial NADH [13], change remarkably according to variation in energy metabolism of animals [2]. Lactate dehydrogenase (LDH) is a tetrameric molecule made up of four subunits of the two parent molecules, the $\mathrm{H}$ and $\mathrm{M}$ subunits, and each tissue has a characteristic composition of isoenzymes [8]. The isoenzyme patterns of $\mathrm{LDH}$ are variable in plasma and leukocytes of each animal species [24]. Activities of enzymes related to energy metabolism in leukocytes are considered to reflect the metabolic states in animal tissues [2, 3, 24]. On the other hand, plasma glucose and insulin concentrations are different between dairy and beef cattle [12, 15, 20, 22]. It has been reported that Japanese Black heifers have higher plasma insulin level at $18 \mathrm{mo}$ of age than at or before $12 \mathrm{mo}$ of age, whilst Holstein heifers have very similar values at all stages [19].

In the present study, activities of enzymes in the malateaspartate shuttle and LDH and LDH isoenzyme pattern were determined in plasma and peripheral leukocytes of the lactating dairy cattle and the fattening beef cattle to clarify one aspect of the differences in energy metabolism between the dairy and beef cattle.

Eight lactating dairy Holstein cows (5 to 8 years old) maintained with good quality hay and concentrates in the Fuji Animal Farm of our university and four fattening Japanese Black Wagyu $\times$ Holstein steers ( 2 years old) kept with high concentrate feed at a farm in Shimane Prefecture were used. Blood was withdrawn from the jugular vein into heparinized tubes, with the animals at rest and unfasted. The plasma was recovered by centrifugation at $4^{\circ} \mathrm{C}$. Leukocytes were isolated by centrifugation with a lymphocyte-isolating solution (ICN Biochemical Inc., Aurora, OH, U.S.A.). Cytosolic and mitochondrial fractions of leukocytes were prepared by the method described previously [23]. The activities of the enzymes were measured by using reported methods: lactate dehydrogenase [11], malate dehydrogenase [7], aspartate aminotransferase (AST) [9] and glutamate dehydrogenase (GLDH) [18]. LDH was used as the marker enzyme in the cytosolic fractions, and GLDH as the marker enzyme in the mitochondrial fractions. MDH and AST were the pivotal enzymes in the malate-aspartate shuttle. Enzyme activities were measured at 24 to $26^{\circ} \mathrm{C}$ and expressed as $\mathrm{U} / l$ (volume activity) in plasma and $\mathrm{mU} / \mathrm{mg}$ of protein (specific activity) in cytosolic and mitochondrial fractions. The enzyme activity (U) was defined as $1 \mu \mathrm{mol}$ of substrate degraded per min. The protein concentrations were determined by the method of Bradford [6] with bovine serum albumin as the standard. The cytosolic MDH/LDH activity ratio (ML ratio) was calculated as $\mathrm{MDH}$-specific activity divided by LDH-specific activity. The ML ratio was investigated as the indicator to evaluate energy metabolic conditions of animal tissues [2, 24]. LDH isoenzymes were detected by a polyacrylamide gel electrophoresis (PAGE) technique described previously [1]. Plasma glucose concentrations were measured by the glucose-oxidase method [10], and immunoreactive insulin (IRI) and free fatty acid (FFA) concentrations were measured by commercial kits, GLAZYME insulin EIA test (Wako Pure Chemical Industries, Tokyo, Japan) and NEFA-C test Wako (Wako Pure Chemical Industries), respectively. All values were presented as means \pm SD and the differences between means were analyzed by Student's $t$-test.

There were no significant differences in plasma glucose and FFA concentrations between dairy and beef cattle. The mean plasma IRI concentrations in the beef cattle were 5.3 folds of those in the dairy cattle. $\mathrm{LDH}$ and $\mathrm{MDH}$ activities in plasma of the beef cattle were significantly higher than 
Table 1. Comparison of concentrations of glucose, free fatty acid and immunoreactive insulin and activities of enzymes in plasma and leukocytes in dairy and beef cattle

\begin{tabular}{lcc}
\hline & Dairy cattle (8) & Beef cattle (4) \\
\hline Plasma & & \\
Glucose (mmol/l) & $3.6 \pm 0.3$ & $4.1 \pm 0.6$ \\
FFA (mEq/l) & $0.30 \pm 0.09$ & $0.34 \pm 0.11$ \\
IRI (pmol/l) & $144 \pm 38$ & $768 \pm 159^{*}$ \\
LDH (U/l) & $1028 \pm 164$ & $1874 \pm 334^{*}$ \\
MDH (U/l) & $283 \pm 49$ & $427 \pm 70^{*}$ \\
AST (U/l) & $62 \pm 10$ & $76 \pm 8$ \\
Leukocyte & & \\
Cytosol & & \\
MDH (mU/mg) & $285 \pm 55$ & $294 \pm 46$ \\
LDH (mU/mg) & $472 \pm 123$ & $398 \pm 56$ \\
ML ratio & $0.60 \pm 0.08$ & $0.74 \pm 0.03^{*}$ \\
AST (mU/mg) & $37 \pm 7$ & $44 \pm 6$ \\
Mitochondria & & \\
GLDH (mU/mg) & $36 \pm 10$ & $42 \pm 7$ \\
MDH (mU/mg) & $386 \pm 68$ & $481 \pm 77$ \\
AST (mU/mg) & $68 \pm 12$ & $74 \pm 14$ \\
\hline
\end{tabular}

Values are presented as mean $\pm \mathrm{SD}$.

The number in parentheses indicate the number of animals examined.

*Significantly higher $(\mathrm{p}<0.01)$ than the value of dairy cattle.

those of the dairy cattle. LDH activities in cytosolic fractions of the beef cattle were lower than those in the dairy cattle. The cytosolic ML ratio in leukocytes of the beef cattle was significantly higher than that in the dairy cattle. Although all enzymes activities measured in mitochondrial fractions of the beef cattle were higher than those of the dairy cattle, the difference was not significant (Table 1). Representative electrophoretic patterns of LDH isoenzymes in the cattle are shown in Fig. 1. In both the dairy and the beef cattle plasma, LDH-1, -2 and -3 were dominant and LDH-4 was scant. LDH-5 was scarcely observed in plasma of the cattle. In leukocytes of the dairy and beef cattle, 5 bands of LDH isoenzymes were observed and LDH-1, -2 and -3 were dominant.

Lactating Holstein cows and fattening Japanese Black Wagyu $\times$ Holstein steers were used in the present study as most popular dairy and beef cattle in Japan, respectively. After sexual maturation, Japanese Black heifers had markedly higher basal levels of plasma insulin than Holstein heifers at 18 mo of age [19]. In the present study, plasma IRI concentrations in beef cattle at 24 mo of age were significantly higher than those in Holstein dairy cattle. Although infusion of glucose does not stimulate insulin secretion, infusion of the VFA propionate, but not acetate, stimulates insulin secretion in ruminants [16]. When a roughage diet was fed, the proportion of propionate as gluconeogenesis source in the rumen VFA was low compared with a concentrate-based diet fed to ruminants [21]. Plasma insulin concentrations were lower for a high-roughage diet than for a high-concentrate diet in sheep [17]. Insulin secretory responses are varied with changes in feeding diets in beef cattle [19]. High concentrations of plasma IRI observed in the beef cattle may be induced by increasing of propionate

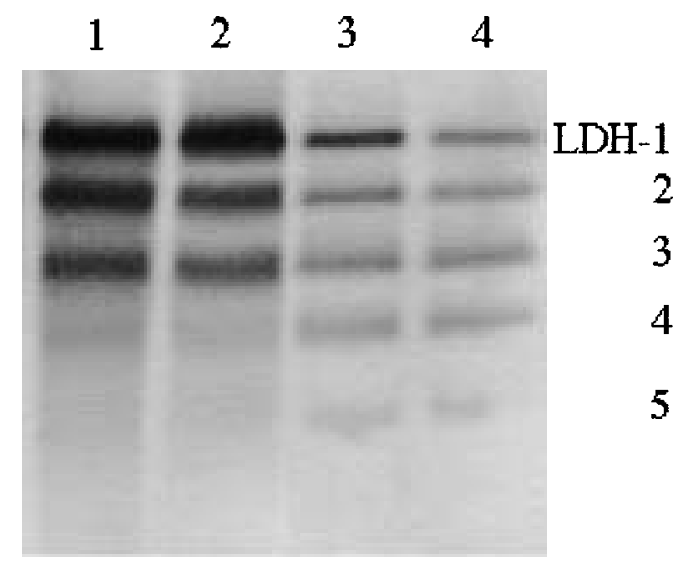

Fig. 1. Representative electrophoretic patterns of $\mathrm{LDH}$ isoenzymes in plasma and cytosolic fractions of leukocytes of dairy and beef cattle. Lane 1, dairy cattle plasma; lane 2 , beef cattle plasma; lane 3 , dairy cattle leukocytes; lane 4 , beef cattle leukocytes.

concentrations accompanied by high-concentrate diet feeding. The relationship between plasma metabolites and insulin concentrations should be further studied in many cattle with different feeding conditions. Activities of $\mathrm{LDH}$ and $\mathrm{MDH}$ in the beef cattle plasma were also significantly higher than those in the dairy cattle. LDH-1, -2 and -3 bands were stained strongly in the dairy and beef cattle plasma by isoenzyme analysis. LDH isoenzyme pattern in the cattle plasma was inclined to be affected by the change in metabolic condition of liver with dominance of LDH-1 and -2 [14]. High activities of LDH and MDH in the beef cattle plasma possibly suggest that energy metabolism is activated in livers of beef cattle. High ML ratio in leukocytes is considered to reflect elevation of energy metabolism, including ATP production, in various animal tissues [3, 24]. Significant increase in the ML ratio was observed in leukocytes of race horse with continuous hard training [3] and tumor tissues with hyperplasia [4]. On the other hand, the ML ratio is significantly decreased in leukocytes of diabetic dogs with insulin deficiency [5]. ML ratio in the beef cattle leukocytes was $23 \%$ higher than that in the dairy cattle, and this increase may indicate higher elevation in energy metabolism in tissues than that in dairy cattle. The relationship between increase in the ML ratio and the high plasma IRI concentrations in beef cattle should be further studied. In the present study, energy metabolism in the beef cattle appeared to differ from that in the dairy cattle, however, the number of cattle examined was small and amount of ATP in leukocytes or compositions of diets were not clarified. Changes of activities of enzymes and ML ratio in leukocytes should be further studied in many kinds of cattle with various breeding conditions including changes in feeding diets to investigate the availability as indicators to evaluate energy metabolism in cattle. 
ACKNOWLEDGEMENT. The authors are grateful to Mr. N. Matsunaga at Matsunaga Farm (Shimane, Japan) for his help in taking samples from the beef cattle.

\section{REFERENCES}

1. Arai, T., Sasaki, M., Tanaka, J. and Oki, Y. 1988. Jpn. J. Vet. Sci. 50: 287-290.

2. Arai, T., Takahashi, M., Araki, K. and Washizu, T. 2001. Vet. Res. Commun. 25: 577-583.

3. Arai, T., Hosoya, M., Nakamura, M., Magori, Y., Uematsu, Y. and Sako, T. 2002. Res. Vet. Sci. 72: 241-244.

4. Arai, T., Ogawa, T., Hosoya, M., Nakamura, M. and Kawakami, E. 2002. Vet. Res Commun. 26: 347-352.

5. Arai, T., Nakamura, M., Magori, E., Fukuda, H., Mizutani, H., Kawakami, E. and Sako, T. 2002. Res. Vet. Sci. 73: 183-187.

6. Bradford, M.M. 1976. Anal. Biochem. 72: 248-254.

7. Bergmeyer, H.U. and Bernt, E. 1974. pp. 613-617. In: Methods of Enzymatic Analysis, vol. 2 (Bergmeyer, H.U. ed.), Academic Press, New York.

8. Dawson, D.M., Goodfriend, T.K. and Kaplan, N.O. 1964. Science 143: 929-933.

9. Horder, M. and Rej, R. 1983. pp. 444-456. In: Methods of Enzymatic Analysis, vol. 3, 3rd ed. (Bergmeyer, H.U. ed.), $\mathrm{VCH}$, New York.

10. Huggett, A.G. and Nixon, D.A. 1957. Lancet 2: 368-370.

11. Kaloustian, H.D., Stolzenbach, F.E., Everse, J. and Kaplan, N.O. 1969. J. Biol. Chem. 244: 2891-2901.

12. Landau, S., Braw-Tal, R., Kaim, M., Bor, A. and Bruckental, J. 2000. Anim. Reprod. Sci. 64: 181-197.
13. MacDonald, M.J. 1982. Arch. Biochem. Biophys. 213: 643649.

14. Nonaka, T., Arai, T., Shibato, T. and Oki, Y. 1989. Jpn. J. Vet. Sci. 51: 434-436.

15. Oka, A., Iwaki, F., Dohgo, T., Ohtagaki, S., Noda, S., Shinozaki, T., Endoh, O. and Ozaki, M. 2002. J. Anim. Sci. 80: 1005-1011.

16. Sano, H., Hattori, Y., Todome, Y., Tsuruoka, J., Takahashi, H. and Terashima, Y. 1993. J. Anim. Sci. 71: 3414-3422.

17. Sano, H., Takebayashi, A., Kodama, Y., Nakamura, K., Ito, H., Arino, Y., Fujita, T., Takahashi, H. and Ambo, K. 1999. J. Anim. Sci. 77: 2564-2573.

18. Schmidt, E. 1974. pp. 650-655. In: Methods of Enzymatic Analysis, vol. 2 (Bergmeyer, H.U. ed.), Academic Press, New York.

19. Shingu, H., Hodate, K., Kushibiki, S., Ueda, Y., Watanabe, A., Shinoda, M. and Matsumoto, M. 2001. Comp. Biochem. Physiol. 130C: 259-270.

20. Sternbauer, K. and Luthman, J. 2002. Acta Vet. Scand. 43: 107-114.

21. Sutton, J.D., Hart, IC., Broster, W.H., Elliott, R.J. and Schuller, E. 1986. Br. J. Nutr. 56: 181-192.

22. Swanson, K.C., Richards, C.J. and Harmon, D.L. 2002. J. Anim. Sci. 80: 1112-1116.

23. Washizu, T., Kuramoto, E., Abe, M., Sako, T., and Arai, T. 1998. Vet. Res Commun. 22: 187-192.

24. Washizu, T., Nakamura, M., Izawa, N., Suzuki, E., Tsuruno, S., Washizu, M., Nakajo, S. and Arai, T. 2002. Vet. Res. Commun. 26: 341-346. 